\title{
Kohesi pada Teks Biografi Siswa SMK Kelas XI
}

\author{
Campin Veddayana ${ }^{1}$, Fenny Anita ${ }^{2}$, Ricky Setya Prayoga ${ }^{3}$ \\ Universitas Abdurrab ${ }^{1,2}$, Universitas Negeri Malang ${ }^{2}$ \\ campin.veddayana@univrab.ac.id
}

DOI: $\underline{\text { https://doi.org/10.32528/bb.v6i1.3916 }}$

First received: 10-12-2020

Final proof received: $15-03-2021$

\begin{abstract}
ABSTRAK
Menulis teks biografi menjadi salah satu kompetensi yang harus dimiliki oleh siswa SMK melalui pembelajaran Bahasa Indonesia. Penggunaan pilihan peranti linguistik untuk membangun kohesi pada teks biografi berbeda dengan teks yang lainnya. Oleh sebab itu diilakukan penelitian yang bertujuan untuk mengetahui penggunaan kohesi dalam teks biografi karya siswa kelas XI SMK Negeri di Malang. Data penelitian diperoleh dari teks biografi yang disusun oleh siswa kelas XI SMK. Data penelitian tersebut diinterpretasi dengan melalui tahapan reduksi, kodifikasi, analisis, dan penarikan kesimpulan. Penelitian ini dilakukan dengan menggunakan pendekatan kualitatif-deskriptif. Dari hasil penelitian ditemukan bahwa peranti kohesi gramatikal maupun kohesi leksikal digunakan dalam teks biografi siswa kelas XI SMK. Peranti kohesi gramatikal yang digunakan meliputi referensi, subtitusi, elipsis, dan konjungsi. Sedangkan kohesi leksikal yang digunakan meliputi reiterasi dan kolokasi. Secara keseluruhan, temuan peranti kohesi pada teks biografi ini didominasi oleh gramatikal konjungsi. Temuan ini sesuai dengan salah satu ciri kebahasaan teks biografi yaitu adanya pemaparan urutan atau kronologis peristiwa yang dihubungkan dengan konjungsi.
\end{abstract}

Kata kunci: kohesi gramatikal; kohesi leksikal; teks biografi

\begin{abstract}
Writing biographical texts is one of the competences that must be possessed by vocational students through Bahasa Indonesia course. The use of selected linguistic tools to build cohesion at each stage of a biographical text is different from other texts. Therefore, the research that aimed to determine the use of cohesion in the biographical texts which written by grade XI students of SMK Negeri in Malang was conducted. The research data were obtained from biographical texts compiled by XI grade students of SMK. The research data are interpreted through stages of reduction, codification, analysis, and drawing conclusions. The research data analysis was carried out using a qualitative-descriptive approach. The research found that the grammatical cohesion and lexical cohesion devices are used in the biographical texts of the XI grade students of SMK. Grammatical cohesion which used in the biograpical text involves
\end{abstract}


reference, substitution, ellipsis and conjunction. Meanwhile, the lexical cohesion used includes reiteration and collocation. Overall, the findings of cohesion devices in this biographical text are dominated by grammatical conjunctions. This finding is consistent with one of the linguistic features of the biographical text, namely the sequence or chronological description of events associated with conjunctions. In addition, reiteration markers which are lexical cohesion devices are also used significantly in the biographical texts of students.

\section{Keywords: gramatical cohesion; lexical cohesion; biographical text}

\section{PENDAHULUAN}

Kemampuan menulis adalah satu di antara kemampuan berbahasa yang harus dikuasai peserta didik. Kemampuan menulis teks biografi menjadi salah satu kompetensi yang harus diperoleh siswa SMK melalui pembelajaran Bahasa Indonesia. Melalui penulisan teks biografi peserta didik akan mampu mengembangkan ide, gagasan, pikiran ke dalam tulisannya (Gunawan et al., 2020; Navia et al., 2018). Teks biografi merupakan teks yang berisi tentang kisah riwayat seseorang yang dituliskan oleh orang lain, meliputi pengalaman kesuksesan dalam hidup seseorang tersebut (Kemendikbud, 2016). Teks biografi menjadi bahan pembelajaran yang penting sebab melalui teks biografi sesorang akan memperoleh inspirasi dari kisah dari tokoh tersebut. Namun agar nilai-nilai serta makna dari sebuah teks termasuk teks biografi dapat dipahami dengan baik diperlukan unsur pembentuk teks yang sesuai (Nurcahyo et al., 2020). Hal tersebut dilakukan agar tidak terjadi kesalahan penafsiran terhadap ide atau gagasan yang tertuang dalam teks tersebut.

Secara umum terdapat ciri-ciri penggunaan kebahasaan pada teks biografi. Ciri-ciri kebahasaan teks biografi, yaitu (a) menggunakan kata pronomina, (b) mendeskripsikan identitas pelaku, waktu dan tempat, (c) penggambaran peristiwa atau waktu kejadian menggunakan keterangan waktu (lampau), (d) pemaparan urutan atau kronologis peristiwa dengan konjungsi. Konjungsi yang digunakan untuk menghubungkan klausa dengan klausa dalam urutan beberapa kejadian secara kronologis (Anderson \& Anderson, 1997).

Salah satu faktor yang memudahkan pembaca agar memahami sebuah teks adalah koherensi teks tersebut (Laila \& Nova, 2020). Penggunaan peranti kohesi dapat mewujudkan teks yang koheren. Kohesi menjadi unsur penting dalam menyusun sebuah teks. Kohesi pada teks diartikan sebagai keruntutan dan kepaduan penggunaan bahasa dalam teks yang sesuai dengan konteksnya. Oleh sebab itu seorang penulis sebaiknya menguasai penggunaan kohesi dalam teks (Nisa, 2019). Berhubungan dengan hal tersebut Halliday \& Hasan (2014) menyatakan bahwa kohesi merupakan hubungan makna yang utuh dalam teks. Kohesi termasuk pemahaman terhadap makna yang membentuk suatu hubungan dengan teks untuk membuat makna tersebut dapat dipahami oleh pembacanya. Peranti kohesi merupakan hubungan kohesif ditandai dengan penggunaan peranti formal yang berupa bentuk linguistik (Rani et al., 2006). Meskipun unsur kohesi tidak selalu menjamin terbentuknya wacana yang utuh dan koheren, namun idealnya teks yang baik harus memiliki syarat-syarat kohesi sekaligus koherensi (Mujianto, 2019). 
Peranti kohesi dapat dikelompokkan menjadi dua, yaitu kohesi gramatikal dan kohesi leksikal (Halliday \& Hasan, 2014). Menurut Rani, et al., (2006) peranti kohesi gramatikal merupakan peranti atau penanda kohesi yang melibatkan penggunaan unsurunsur kaidah bahasa, digunakan untuk menghubungkan ide antarkalimat cukup terbatas ragamnya. Keterkaitan antarkalimat dinyatakan dengan unsur gramatikal (Sinambela et al., 2019). Kohesi gramatikal dapat dilihat dari segi referensi eksofora dan endofora, referensi anafora dan katafora, peggantian (substitusi), peranti konjungsi, peranti urutan waktu, peranti pilihan, peranti alahan, peranti parafrase, peranti ketidakserasian, peranti serasian, peranti tambahan (aditif), peranti pertentangan (kontras), peranti perbandingan (komparatif), peranti sebab-akibat, peranti harapan (optatif), peranti ringkasan dan simpulan, peranti misalan atau contohan, peranti keragu-raguan (dubitatif), peranti konsesi, peranti tegasan, dan peranti jelasan, konjungsi. Sementara itu, peranti kohesi leksikal dapat berupa kata atau frasa bebas yang mampu mempertahankan hubungan kohesif dengan kalimat mendahului atau yang mengikuti. Dengan demikian, kohesi leksikal dapat dilihat dari beberapa aspek seperti reiterasi ulangan penuh, reiterasi ulangan dalam bentuk lain, kolokasi.

Penggunaan atau pilihan peranti linguistik untuk membangun kohesi pada setiap tahap teks biografi berbeda dengan teks yang lainnya. Sebab dalam menulis teks biografi penulis harus mengerti dan paham dari sudut pandang mana akan menuliskan tokoh tersebut sehingga orang yang membaca biografi tersebut dapat menangkap pesan yang disampaikan penulis. Oleh sebab itu dilakukan penelitian bertujuan untuk mengetahui penggunaan kohesi dalam teks biografi karya siswa kelas XI SMK. Dari hasil penelitian ini diharapkan dapat diperoleh deskripsi objektif tentang penggunaan kohesi dalam teks biografi siswa kelas XI SMK. Selanjutnya, penjabaran tersebut dapat dimanfaatkan sebagai upaya pembinaan aspek keterampilan menulis dan aspek keterampilan berbahasa lainnya.

\section{METODE PENELITIAN}

Penelitian dilaksanakan dengan pendekatan kualitatif-deskriptif. Data penelitian diperoleh dari karya 30 orang siswa kelas IX di salah satu SMK Negeri di Malang berupa teks biografi. Penelaahan teks biografi dilakukan untuk memperoleh data penelitian. Data penelitian tersebut diproses dengan melalui tahapan reduksi, kodifikasi, analisis, dan penarikan kesimpulan. Hasil telaah teks diklasifikasikan ke dalam tabel panduan analisis data. Data tersebut diklasifikasi berdasarkan jenis peranti kohesi dari teks biografi yang dituliskan oleh siswa.

Pengecekan keabsahan temuan dalam penelitian ini dilakukan dengan mengujicobakan dahulu lembar panduan yang digunakan sebagai instrumen penelitian. Kemudian peneliti mengecek kesesuaian data yang telah diperoleh terhadap tujuan penelitian. Selanjutnya hasil analisis data dijabarkan dalam bentuk deskripsi.

\section{PEMBAHASAN}

Pada penelitian ini dilakukan identifikasi penggunaan peranti kohesi pada biografi yang disusun oleh siswa kelas XI SMK. Telaah peranti kohesi dalam bentuk tulisan lebih 
akurat untuk dikaji daripada sebuah produk lisan karena tulisan tersebut. Hal ini dikarenakan dalam sebuah teks cenderung menggunakan gramatikal, memiliki penataan subordinatif yang lebih banyak, berstruktur subjek predikat, serta menggunakan peranti hubung daripada bentuk teks lisan yang cenderung kurang terstruktur, penataan subordinatifnya lebih sedikit, jarang menggunakan peranti hubung dan berstruktur (Rani et al., 2006). Dari hasil penelitian ditemukan 620 peranti kohesi gramatikal yang terdiri atas 157 gramatikal referensi atau pengacuan, 60 gramatikal subtitusi atau penyulihan, 15 gramatikal elipsis atau pelepasan, dan 388 gramatikal konjungsi atau penghubung. Selanjutnya juga ditemukan 235 peranti kohesi leksikal. Pada data tersebut terdapat 222 leksikal reiterasi atau pengulangan dan 13 peranti kolokasi. Pemaparan beberapa temuan berupa peranti kohesi gramatikal dan leksikal dalam teks biografi karangan siswa kelas XI SMK.

Tabel 1: Peranti Kohesi dalam Teks Biografi Karangan Siswa Kelas XI SMK

\begin{tabular}{|c|c|c|}
\hline Peranti Kohesi & Kutipan & Deskripsi \\
\hline \multirow[t]{4}{*}{$\begin{array}{l}\text { Peranti Kohesi } \\
\text { Gramatikal }\end{array}$} & $\begin{array}{l}\text { (14) Ibuku juga sering sekali } \\
\text { menangis saat dihina. (15) } \\
\text { Terkadang ia tidak jajan karena } \\
\text { tidak dikasih uang, bahkan saat } \\
\text { pulang sekolah tidak bermain } \\
\text { dengan temannya dan lebih } \\
\text { memilih membantu orangtuanya } \\
\text { untuk mencari uang untuk jajan } \\
\text { disekolah serta menabung. } \\
\text { (Dwi/10.W.KG/REF.A.3.15) }\end{array}$ & $\begin{array}{l}\text { Peranti kohesi pada teks biografi tersebut adalah } \\
\text { kohesi gramatikal referensi. Pada kutipan } \\
\text { tersebut menunjukkan bahwa penggunaan kata } \\
\text { atau pronimina ia untuk menunjuk kata atau } \\
\text { kelompok kata atau satuan gramatikal lainnya } \\
\text { yaitu pada ibuku. }\end{array}$ \\
\hline & $\begin{array}{l}\text { (14)Hal itu membuktikan jika } \\
\text { beliau rela berkorban,bekerja } \\
\text { keras. (15) Ia rela untuk banting } \\
\text { tulang demi keluarga. } \\
\text { (Elmi/13.W.KG/SUB.I. 2.14) }\end{array}$ & $\begin{array}{l}\text { Peranti kohesi pada teks biografi tersebut adalah } \\
\text { kohesi gramatikal substitusi. Pada kutipan } \\
\text { tersebut menunjukkan adanya hubungan } \\
\text { gramatikal substitusi dari kata bekerja keras } \\
\text { pada proposisi pertama. Selanjutnya, mengalami } \\
\text { penggantian pada proposisi kedua menjadi } \\
\text { banting tulang. Frasa banting tulang merupakan } \\
\text { metafora pada frasa bekerja keras. Hubungan } \\
\text { kedua frasa yang bersangkutan pada kutipan } \\
\text { tersebut merupakan hubunan metaforis dan } \\
\text { koherensi tetap terjaga karenanya. }\end{array}$ \\
\hline & $\begin{array}{l}\text { (11) Ibuku saat belajar pada } \\
\text { malam hari hanya menggunakan } \\
\text { penerangan berupa lampu } \\
\text { cemplok. (12) hampir setiap hari, } \\
\varnothing \text { selalu bermain petak umpet. } \\
\text { (Danea/1.W.KG/ELI.A.3.12) }\end{array}$ & $\begin{array}{l}\text { Peranti kohesi pada teks biografi tersebut adalah } \\
\text { kohesi gramatikal elipsis. Pada kalimat (8) } \\
\text { kutipan tersebut menunjukkan terdapat subjek } \\
\text { kalimat Yuli yang kemudian dilesapkan pada } \\
\text { kalimat (9). }\end{array}$ \\
\hline & $\begin{array}{l}\text { (22) Mereka dikaruniai } \\
\text { momongan yang bernama Danea } \\
\text { Rehan Pradita dan Devan Alfino } \\
\text { Akmal.(Danea/1.W.KG/KON.I.4. } \\
\text { 22) }\end{array}$ & $\begin{array}{l}\text { Peranti kohesi pada teks biografi tersebut adalah } \\
\text { kohesi gramatikal konjungsi. Pada kutipan } \\
\text { data diatas digunakan kata dan untuk } \\
\text { mengaitkan dua informasi yang bersifat setara. } \\
\text { Informasi anak yang bernama Danea Rehan } \\
\text { Pradita dikaitkan dengan anak yang bernama } \\
\text { Devan Alfino Akmal. Kedua informasi ini } \\
\text { bersifat setara karena keduanya merupakan anak } \\
\text { yang yang dilahirkan bersamaan dan } \\
\text { berlangsung pada waktu yang sama. }\end{array}$ \\
\hline
\end{tabular}




\begin{tabular}{|c|c|c|}
\hline \multirow[t]{2}{*}{$\begin{array}{l}\text { Peranti Kohesi } \\
\text { Leksikal }\end{array}$} & $\begin{array}{l}\text { (20) Ibu ayah selalu mengajarkan } \\
\text { ayah dan anak - anak lainya } \\
\text { tentang kebaikan, seperti kalau } \\
\text { tidak punya apa - apa tidak boleh } \\
\text { mencuri, selalu syukuri apa yang } \\
\text { ada .(21) Ibu ayah tidak pernah } \\
\text { pilih kasih, selalu memberi } \\
\text { semangat belajar dalam } \\
\text { melakukan segala sesuatu, } \\
\text { solidaritas serta pantang } \\
\text { menyerah. (Dana/9.W.KL/REI. } \\
\text { A.4.21) }\end{array}$ & $\begin{array}{l}\text { Peranti kohesi pada teks biografi tersebut adalah } \\
\text { kohesi leksikal reiterasi atau pengulangan. } \\
\text { Pada kutipan data diatas ditemukan adanya } \\
\text { penanda kohesi leksikal reiterasi atau } \\
\text { pengulangan berupa kata ibu ayah yang } \\
\text { sebelumnya sudah disebutkan pada kalimat (20) } \\
\text { dan diulang pada kalimat ( } 21)\end{array}$ \\
\hline & $\begin{array}{l}\text { (7) Disana ayah berangkat tidak } \\
\text { menggunakan alat transportasi } \\
\text { seperti sepeda pancal, becak } \\
\text { atau motor, tetapi jalan kaki. } \\
\text { (Dana/9.W. KL/KOL.I.2.7) }\end{array}$ & $\begin{array}{l}\text { Peranti kohesi pada teks biografi tersebut } \\
\text { adalah kohesi leksikal kolokasi. Pada kutipan } \\
\text { data tersebut kata sepeda pancal, becak atau } \\
\text { motor, memiliki hubungan asosiasi dengan alat } \\
\text { trasnsportasi atau kendaraan. Kolokasi tersebut } \\
\text { bersifat nominal. }\end{array}$ \\
\hline
\end{tabular}

Berdasarkan temuan di atas terlihat bahwa siswa SMK telah mampu menggunakan peranti kohesi gramatikal maupun peranti kohesi leksikal dalam menyusun teks biografi.

\section{Kohesi Gramatikal Referensi}

Hubungan gramatikal dalam teks biografi tersebut dapat diklasifikasikan berdasarkan bentuk bahasa yang digunakan oleh siswa dalam menuliskan teks biografi. Temuan-temuan tersebut sejalan dengan teori kohesi Halliday dan Hasan (2014) yang menyatakan bahwa unsur-unsur gramatikal ini terdiri dari kohesi referensi, kohesi subtitusi, kohesi elipsis, dan kohesi konjungsi. Konsep kohesi gramatikal muncul ke hubungan antarunsur dalam teks yang direalisasikan melalui tata bahasa. Dari data analisis temuan peranti kohesi gramatikal diatas menunjukkan bahwa kohesi dalam teks biografi melibatkan semua alat kohesi yang ada.Peranti kohesi gramatikal yang digunakan didominasi oleh kohesi gramatikal referensi dan konjungsi. Di antara peranti kohesi referensi yang digunakan siswa teridentifikasi peranti kohesi gramatikal referensi endofora. Berikut disajikan contoh data yang menggunakan peranti kohesi gramatikal referensi.

(1) Siti Nawerah atau akrap dipanggil nawerah adalah seorang ibu rumah tangga yang memiliki 3 orang anak. (2) Beliau lahir pada tanggal 9 mei 1975 di bangkalan.(Dino/8.J. REF/PERSO/END/ANA.A.1.2)

Halliday dan Hassan (1979) menyatakan ada dua macam referensi, yaitu refereni eksofora dan referensi endofora. Referensi eksofora adalah pengacuan terhadap anteseden yang terdapat di luar bahasa (ekstratekstual), sementara endofora adalah pengacuan terhadap anteseden yang terdapat di dalam teks (intratekstual) (Arifin, 2012). Jenis peranti kohesi yang disajikan tersebut adalah referensi personal bersifat endofora. Pada kutipan data diatas pronomina beliau pada kalimat (2) mengacu pada frasa pada kalimat (1) yaitu Siti Naweyah yang terdapat pada kalimat sebelumnya. Pengacuan tersebut 
merujuk pada manusia dengan kata ganti orang ketiga. Dengan begitu pembaca tidak bergantung pada pengetahuan terhadap informasi di luar teks untuk memahaminya. Oleh karena itu, peranti kohesi gramatikal tersebut termasuk penggunaan pronomina personal yang tergolong ke dalam referensi anafora. Berikut contoh lain data yang menggunakan referensi endofora.

(17) Tidak ada seorang laki-laki yang mau mendekatinya kecuali Bambang (yang kini menjadi ayahku). (18) pada saat itu, Bambang sangat penasaran kepada Yuli. (Deby/2.J.REF/PERSO/END/KATA.A.3.18)

Peranti kohesi pada teks biografi tersebut adalah referensi persona bersifat endofora. Pada kutipan data diatas, enklitik -nya pada kalimat (17) mengacu pada persona Yuli pada kalimat (18) yang terletak setelahnya. Penggunaan enklitik -nya termasuk ke dalam jenis pronomina persona yang menunjukkan kepemilikan orang ketiga. Pemahaman pembaca terhadap maksud acuan pronomina tersebut bergantung pada pemahaman yang baik terhadap teks (intratekstual).

Dengan pengembangan khusus-umum, siswa mengembangkan ide dengan menuliskan hal yang utama terlebih dahulu dan dilanjutkan dengan keterangannya. Hal ini terlihat pada pemakaian referensi endofora dalam teks biografi di atas, yang meliputi referensi anafora dan referensi katafora. Referensi anafora adalah pengacuan oleh referensi terhadap anteseden yang terletak di kiri (sebelum kalimat), sedangkan referensi katafora adalah pengacuan referensi terhadap anteseden yang terletak di akan (setelah kalimat) (Arifin, 2012; Halliday, 1978).Baik dalam anafora maupun katafora selalu melibatkan satuan lingual yang berperan sebagai 'acuan' dan satuan lingual lain 'yang mengacu'. Satuan lingual yang dijadikan sebagai acuan disebut dengan anaforis dan kataforis. Keduanya secara umum dikenal dengan istilah anteseden. Sifat anaforis hadir jika pengacuan oleh pronomina terhadap anteseden disebutkan dalam kalimat sebelumnya seperti pada data Dino/8.J. REF/PERSO/END/ANA.A.1.2. Sebaliknya, sifat kataforis hadir jika pengacuan pronomina terhadap anteseden disebutkan dalam kalimat sesudahnya seperti pada data Deby/2.J.REF/PERSO/END/KATA.A.3.18. Pada bagian pendahuluan, siswa memakai referensi anafora dalam teks untuk menegaskan dan mengembangkan suatu konsep.

\section{Kohesi Gramatikal Konjungsi}

Selain peranti kohesi gramatikal referensi, yang paling banyak ditemukan adalah peranti kohesi gramatikal konjungsi. Peranti ini yang menjadi ciri utama kebahasaan teks biografi. Konjungsi merupakan salah satu peranti kohesi gramatikal yang menjadi satu dengan pengembangan khusus-umum dalam menulis teks biografi. Peranti kohesi konjungsi menjadi penghubung antarkata, frasa, klausa, ataupun kalimat (Aisyah, 2019). Berikut disajikan contoh data yang menggunakan kohesi gramatikal konjungsi.

(8) Setelah pulang sekolah, Yuli mencari kayu bakar dan ubi untuk dijual.(Deby/2.J.KON/ADI/INTRA.I.2.8) 
Peranti kohesi pada teks biografi tersebut adalah konjungsi aditif intrakalimat. Pada kalimat (8) di atas, digunakan kata dan untuk mengaitkan dua informasi yang bersifat setara. Informasi mencari kayu dan ubi. Kedua informasi ini bersifat setara karena keduanya merupakan aktivitas yang berlangsung pada waktu yang sama. Selain itu juga terdapat peranti kohesi gramatikal konjungsi lanjutan antarkalimat seperti data yang disajikan berikut.

(19) Mereka berlima sampai harus kehujanan kepanasan demi sampaidi Surabaya, karena acara pameran di adakan di Surabaya. (20) Setelah sampai disana empat orang teman ayahku tiba-tiba tidak mau atau membatalkan pamerannya, jadi hanya ayahku yang ikut, karenaternyata biayanya yang sangat mahal.

(Gavinda/28.J. KON/LANJUT/ANTAR.I.4.20)

Jenis peranti kohesi pada teks biografi tersebut adalah konjungsi lanjutan antarkalimat. Pada kutipan (20) dalam data Gavinda/28.J. KON/LANJUT/ANTAR.I.4.20 terdapat dua peranti kohesi penanda hubungan lanjutan, yaitu kata frasa sesudah itu. Penggunaan kata setelah itu, menunjukkan bahwa ide yang mengikuti kata itu sebagai ide lanjutan yang tidak dapat diletakkan di awal.

Peranti kohesi gramatikal konjungsi menjadi peranti yang paling banyak ditemukan dalam teks biografi siswa. Hal tersebut disebabkan karena pemakaian konjungsi sangat penting dan berpengaruh dalam pembentukan tekstual. Penggunaan yang kurang tepat atau bahkan tidak sesuai dalam satu teks dapat mengakibatkan makna teks yang tersampaikan menjadi berbeda dengan yang dimaksudkan. Hal tersebut senada dengan pendapat Abdul Rani, et al., (2006) yang menyatakan bahwa konjungsi juga digunakan untuk merangkaikan atau mengikat beberapa proposisi dalam teks agar perpindahan ide dalam wacana itu terasa lembut sehingga dipahami oleh pembaca. Dapat disimpulkan penanda konjungsi merupakan satu unit bagian yang penting dan tidak dapat terlepas dalam sebuah melalui proses yang dimulai dari arti (semantiknya) kemudian membantuk tatanan bahasa yang kemudian direlisasikan dalam ekspresi menjadi sebuah teks yang utuh sehingga dapat dipahami oleh semua pembacanya. Keterpahaman teks melalui bahasa tersebut tidak terlepas dari sistem semiotiknya.

Secara keseluruhan, temuan peranti kohesi gramatikal konjungsi pada teks biografi ini didominasi oleh gramatikal konjungsi yang menyatakan makna 'tempo'. Konjungsi yang menyatakan makna 'tempo' adalah jika dua kalimat tersebut dihubungkan konjungsi yang menyatakan waktu (Arifin, 2012). Temuan ini sesuai dengan salah satu ciri kebahasaan teks biografi yaitu adanya pemaparan urutan atau kronologis peristiwa yang dihubungkan dengan konjungsi (Anderson \& Anderson, 1997).

Bahasa berperan sebagai suatu sistem arti dan sistem bentuk dan ekspresi untuk merealisasikan arti tersebut melalui teks yang diwujudkan salah satunya dengan bentuk tulisan atau teks. Untuk menjadikan bahasa agar bermakna, salah satunya dengan penggunaan konjungsi. Kehadiran penanda konjungsi terdapat hampir pada keselurahan teks yang telah dianalisis. Tanpa adanya kohesi konjungsi, orang bisa kehilangan konteks 
kalimat yang menyebabkan terjadinya miss komunikasi. Penggunaan konjungsi yang tepat pula membantu terciptanya sebuah teks yang koheren. Tautan dalam teks semakin erat jika alat kohesi yang digunakan semakin efektif dan intensif. Hal tersebut didukung pula oleh pendapat Chaer (2003) yang menyatakan bahwa kalimat dalam satuan sintaksis yang disusun dari konstituen dasar yang dilengkapi dengan konjungsi untuk mempermudah menangkap makna dari apa yang disampaikan.

\section{Kohesi Leksikal Reiterasi}

Selain peranti kohesi gramatikal, di dalam teks biografi karya siswa SMK juga ditemukan penggunaan peranti kohesi leksikal. Peranti kohesi leksikal yang teridentifikasi berupa leksikal reiterasi dan leksikal kolokasi. Tujuan digunakannya aspek-aspek leksikal di dalam teks biografi adalah untuk menegaskan pentingnya suatu gagasan atau ide yang disampaikan melalui penjabaran (Asih, 2020; Haidir, 2019). Secara umum, peranti kohesi leksikal berupa kata atau frasa bebas yang mampu mempertahankan hubungan kohesif dengan kalimat mendahului atau yang mengikuti. Dari data analisis temuan peranti kohesi leksikal diatas menunjukkan bahwa reiterasi atau pengulangan banyak digunakan dibandingkan dengan kolokasi dalam menuliskan teks biografi. Hal tersebut dikarenakan teks biografi lebih menonjolkan pada karakter atau tokoh pada cerita yang akan dibahas. Tokoh atau karakter dalam biografi tersebut membuat identitas tersendiri bagi penulis sehingga identitas yang diberikan kemudian menjadi makna dan kekuatan dalam teks biografi tersebut. Makna dalam perpaduan tersebut membuat pembaca dapat mendalami kisah dalam teks biografi tersebut. Data yang menggunakan kohesi leksikal reiterasi disajikan sebagai berikut.

(8) Ibuku pertama kali sekolah di TK, setelah 2 tahun di TK dan meneruskan ke SDN Saptorenggo 02. (9) Ibuku selalu berjalan dan jalannya pun belum diaspal jadi, kalau hujan jalannya becek. (Danea/1.J.REI/REP/UP.A.3.9)

Reiterasi adalah penyebutan kembali suatu unit leksikal yang sama yang telah disebut sebelumnya (Halliday, 1978). Peranti kohesi pada data tersebut adalah repetisi penuh antarkalimat. Pada kutipan (9) di atas terdapat pengulangan kata ibuku yang merupakan jenis reiterasi ulangan penuh. Kata tersebut diulang sebanyak dua kali dalam paragraf itu dan tetap menduduki fungsi sebagai subjek di masing-masing kalimatnya. Oleh karena itu, pengulangan pada kutipan di atas dapat digolongkan ke dalam reiterasi ulangan penuh. Data lain yang juga menggunakan kohesi leksikal reiterasi disajikan sebagai berikut.

(4) Pada masa kanak-kanak ibu saya tinggal di Dusun Sidodadi, Desa Simo, Kecamatan Ngantang, Kabupaten Malang. (5) Ibuku seorang putri tunggal dari 3 bersaudara. (Elsa/14.J.REI/REP/UBL.A.1.5)

Peranti kohesi pada teks biografi tersebut adalah repetisi bentuk lain antarkalimat. Pengulangan dengan bentuk lain terdapat pada kutipan (5) di atas. Kata ibu saya diulang 
kembali dengan bentuk lain yaitu kata ibuku. Kedua kata ini berbeda tetapi memiliki acuan yang sama. Acuan keduanya adalah 'ibu'.

\section{Kohesi Leksikal Kolokasi}

Peranti kohesi leksikal kolokasi adalah relasi makna leksikal yang berdekatan antara suatu unsur dan unsur lain (Arifin, 2012). Data kalimat yang menggunakan leksikal kolokasi disajikan sebagai berikut.

(9) Ibu saya memiliki semangat pantang menyerah dan membanting tulang untuk mencari uang. (Dicky /7.J.KOL.I.2.9)

Peranti kohesi pada teks biografi tersebut adalah kolokasi intrakalimat. Pada kalimat (9) frasa pantang menyerah dan membanting tulang merupakan kolokasi yang mencerminkan kesamaan asosiasi atau kemungkinan adanya beberapa kata dalam lingkungan yang sama (Halliday, 1978). Penanda leksikal kolokasi lebih sedikit digunakan daripada reiterasi karena dalam teks biografi penggunaan kolokasi hanya berperan sebagai pelengkap.

\section{SIMPULAN}

Berdasarkan hasil penelitian terlihat bahwa siswa SMK telah mampu menggunakan peranti kohesi gramatikal maupun peranti kohesi leksikal dalam menyusun teks biografi. Peranti kohesi gramatikal yang digunakan meliputi referensi, subtitusi, elipsis, dan konjungsi. Sedangkan kohesi leksikal yang digunakan meliputi reiterasi dan kolokasi. Secara keseluruhan, temuan peranti kohesi pada teks biografi ini didominasi oleh gramatikal konjungsi. Temuan ini sesuai dengan salah satu ciri kebahasaan teks biografi yaitu adanya pemaparan urutan atau kronologis peristiwa yang dihubungkan dengan konjungsi bermakna 'tempo'.

\section{REFERENSI}

Aisyah, N. (2019). Analisis Kohesi dan Koherensi Wacana pada Lembar Kerja Siswa Bahasa Indonesia untuk SMA/MA/SMK/MAK Kelas XI. Jubindo: Jurnal Ilmu Pendidikan Bahasa Dan Sastra Indonesia, 4(3), 151-160.

Anderson, M., \& Anderson, K. (1997). Text Types in English (Vol. 2). Macmillan Education AU.

Arifin, B. (2012). Alat Kohesi Wacana Bahasa Indonesia (I). Gunung Samudera.

Asih, K. M. (2020). Kohesi Dan Koherensi Dalam Wacana Surat Kabar Jawa Pos Rubrik Zetizen. BAPALA, 7(1).

Chaer, A. (2003). Seputar Tata Bahasa Baku Bahasa Indonesia. PT. Rineka Cipta.

Gunawan, F. I., Supendi, D. A., \& Setiadi, D. (2020). Analisis Kohesi Gramatikal antar Kalimat pada Teks Narasi Siswa sebagai Bahan Pembelajaran Menulis di MTs 
Assalam Sukabumi. Lingua Franca: Jurnal Bahasa, Sastra, Dan Pengajarannya, 4(1), 41-53.

Haidir, H. (2019). Analisis Wacana Kohesi dan Koherensi pada Wacana Iklan Politik Pemilihan Gubernur Sumatera Utara (PILGUBSU 2018). Jurnal Bahtera-Jurnal Pendidikan Bahasa Sastra Dan Budaya, 6(12).

Halliday, M. A. K. (1978). Language as Social Semiotic: The Social Interpretation of Language and Meaning. Hodder Arnold.

Halliday, M. A. K., \& Hasan, R. (2014). Cohesion in english. Routledge.

Halliday, M. A. K., \& Ruqaiya, H. (1976). Cohesion in English. London, Longman.

Kemendikbud. (2016). Bahasa Indonesia. PT. Intan Pariwara.

Laila, F., \& Nova, S. (2020). Analisis Penggunaan Kohesi dan Koheresi Karangan Eksposisi Siswa Kelas X SMK Negeri 2 Padang Panjang. Inovasi Pendidikan, $7(1)$.

Mujianto, G. (2019). Piranti Kohesi dalam Wacana Tulis Guru SMA/SMK Muhammadiyah Kabupaten Malang. KEMBARA Journal of Scientific Language Literature and Teaching, 3(2), 210-233.

Navia, Y., Asri, Y., \& Afnita, A. (2018). Pengaruh Penggunaan Strategi Pembelajaran Inkuiri Terhadap Keterampilan Menulis Teks Biografi. Pendidikan Bahasa Indonesia, 7(3), 431-439.

Nisa, K. (2019). Hubungan Penguasaan Piranti Kohesi dan Koherensi dengan Keterampilan Menulis Eksposisi. JURNAL DIALOG, 8(2), 917-926.

Nurcahyo, R. J., Nandasari, V., \& Zulaikha, R. D. (2020). Kohesi Wacana Dalam Kumpulan Puisi Berguru Kepada Rindu Karya Acep Zamzam Noor. Imajeri: Jurnal Pendidikan Bahasa Dan Sastra Indonesia, 2(2), 190-199.

Rani, A., Arifin, B., \& Martutik. (2006). Analisis Wacana: Sebuah Kajian Bahasa dalam Pemakaian. Bayumedia Publishing.

Sinambela, K., Simanjuntak, T., \& Telaumbanua, S. (2019). Aspek Kohesi Gramatikal dan Leksikal pada Karangan Eksposisi Kelas X SMA Negeri 1 Laguboti Kabupaten Toba Samosir TA 2018\2019. Jurnal Genre (Bahasa, Sastra, Dan Pembelajarannya), 1(1), 9-17. 